\title{
RFID Based Network Administration with Personal Identification
}

\author{
R.S. Sidharthraj, K. Subbulakshmi, R. Mohan Raj
}

\begin{abstract}
The concept of RFID based power consumption finds application in software companies. The computers present in the software agency are accessed at the same time. There are cases where some user may forget to shut down the computer which may result in wastage of more energy and money. This RFID technology can be employed to design an automatic energy-saving system to be usedin computer labs. The computers can be made to shut down or suspend automatically when not in use We can therefore save unnecessary energy waste and decrease carbon dioxide emissions and slow global warming. Keywords: RFID-based energy consumption, radio frequency identification technology.
\end{abstract}

Keywords: RFID, Network Administration

\section{INTRODUCTION}

RFID stands for "Radio Frequency Identification." The RFID tag is given with a miniaturized computer chip used to store information of any item to be represented as a distinctive code known as an Electronic Product. Code (EPC). The RFID tag contains a microchip connected to the antenna that is packed in a compact manner. The package is provided in such a way that it can be fixed to any item that needs to be tracked. The antenna embedded in the RFID tag receives the incoming signals from the RFID reader or scanner and then sends the signal back with some additional data. Tags could be of two kinds:

i Active Tag

ii .Passive Tag

Active tagsare provided with a battery which providespartial or a complete power for the antenna and the internal circuitry of the tag. Certain active tags can also be fitted with replaceable batteries so that it can be used for years And its advantages are[1],[3],[5],

- It can be used at a distance of about one hundred feet or even more.

- Other sensors that work on electricity also can be used.

Passive tags not equipped with a battery ; the RFID reader should supply the tag energy. When a passive RFID tag comes across radio waves from an RFID reader, a magnetic field. And the benefits are,

Revised Manuscript Received on August 22, 2019.

R.S. Sidharthraj, Department of Electronics and Communication Engineering, Bharath Institute of Higher Education and Research, Chennai, Tamilnadu, India. E Mail - sidarthraj93@gmail.com

K. Subbulakshmi, Department of Electronics and Communication Engineering, Bharath Institute of Higher Education and Research, Chennai, Tamilnadu, India. E Mail -p.sudha50@gmail.com

R. Mohan Raj, Department of Electronics and Communication Engineering, Bharath Institute of Higher Education and Research, Chennai, Tamilnadu, India. E Mail - dspmohanraj@gmail.com
- No battery usage; Lifetime for the passive is about twenty years or more.

- Low manufacturing cost.

\section{A. Complement to barcode}

RFID tags can never act as a substitute, for other type of barcodes, because they arevery expensive. RFID tag has the advantage of using many data sources on asingle item. Barcodes can be generated and distributed via e-mail or mobile phones[2],[4],[6] .

Many terabytes of memory are needed to store data related to object surveillance. RFID data should be filtered and categorized in order to provide useful information. Products can be monitored by pallet using RFID tags and can be tracked at the parcel level using the Universal Product Code (UPC) or EAN from any distinctive barcode.

\section{B. RFID reader}

An antenna that emits radio waves is supplied to the RFID reader ; the tag gets the information and sends it back. The RFID reader is usually used to interrogate the RFID tag. The distance at which the tag can be read relies on a number of variables, such as the reading range. Frequency used for detection and antenna gain. It also relies on the type of polarization of the viewer and the transponder antenna. The reading range also relies on how the antennas are aligned with each other. The position where the tag is positioned on the item to be recognized will also affect the read variety of the RFID scheme[7],[9],[11].

RFID Range depends on:

- Transmitted power

- Sensitivity and efficiency of the receiver

- Antenna

- Frequency

\section{WORKING OF RFID}

Long checkout queues at the shop are one of the greatest issues that arise during our shopping experience. These lines could disappear when the Universal Product Code (UPC) bar code is substituted by intelligent labels or radio frequency identification (RFID) tags. RFID tags are also called intelligent bar codes because they can talk to a networked system to track every product that you put in your shopping cart[8],[10],[12].

A few requirements are accepted by the RFID scheme. But the issue has been that there is no widely accepted standard. Many of the RFID apps were closed due to problems in the multiple competing norms. Standards and theirs Specifications may be established at the global, domestic, industrial or trade association level, as well as by individual organisations. Most of the industry norms and 
requirements set by individual organisations are based on global norms for execution and the provision of a broad spectrum of accessible products. Today, the two biggest RFID drivers are the Department of Defense (DOD) and Wal-Mart. Both have mandated their top vendors to use RFID technology during the shipment of their products to their distribution centers.

\section{COMPONENTS OF AN RFID SYSTEM}

\section{A. Project description}

Radio Frequency Identification (RFID) is a generic term used to describe a system that transfers the identity (as a unique serial number) of an object or person wirelessly using radio waves. RFID technology does not require a line of sight for its communication.. RFID reader connected to the server through microcontroller helps the user to access their respective system. The microcontroller used is ATMEL AT89S52. When a user enters the lab, he / she must demonstrate their corresponding RFID card to the RFID reader.The power status of the computer system located to that particular staff will be changed from sleep mode to normal mode automatically through the server. Again, the power status of the computer system can be changed from normal mode to sleep mode, when the staff shows the RFID card to the server for the second time[8],[10],[12]. Also, the in-time and out-time of the user is registered on the server based on the time at which the RFID card is been swapped by a particular user. Hence there is efficient control of staff's attendance in the lab, by simultaneously saving power.

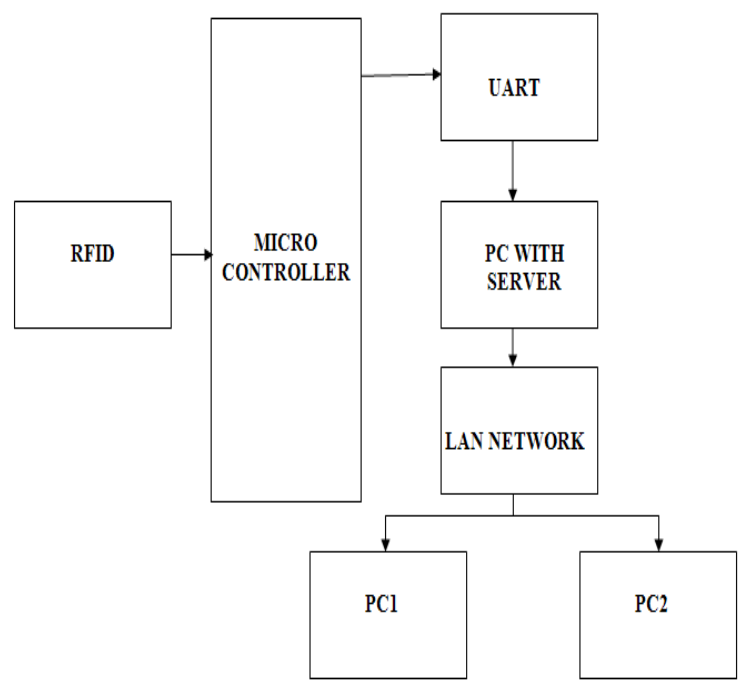

Fig 3.1 Main Block Diagram

\section{B. AT89S52 microcontroller}

A microcontroller (also called a microcontroller unit, MCU or $\mu \mathrm{C}$ ) includes a tiny computer attached to a single embedded circuit consisting of a straightforward CPU along with other extra features. like serial I/O, analog I/O, crystal oscillator, timers, watchdog timer etc. Program memory can also be provided on the chip, in the form of OTP ROM or NOR flash.A typical amount of RAM can also be included in the chip[14],[16],[18].

The AT89S52 is an 8-bit CMOS microcontroller. It consumes low power. Gives you high-performance. Has a programmable $8 \mathrm{~K}$ byte flash memory built into the scheme. Atmel's high-density, non-volatile memory technology is used to manufacture the microcontroller.. It is consistent with the Industrial Standard Instructions set out in the specification of 80C51. Program memory is reprogrammable in-system. Alternatively, a standard non-volatile memory program can be used. It includes a versatile 8-bit CPU coupled with a programmable Flash memory on a single integrated chip. This makes the Atmel AT89S52 a strong microcontroller. It provides a highly flexible and cheaper solution for most embedded control apps.

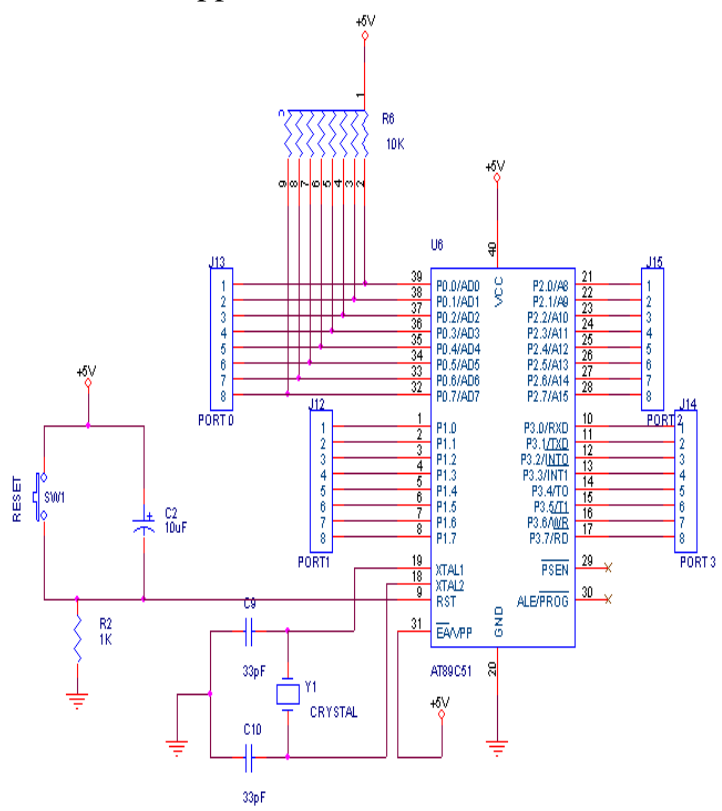

Fig 3.2 circuit diagram of atmel

\section{RFID card reader}

The RFID tag is usually applied to or attached to an object, animal or individual for monitoring and identification with the assistance of radio waves. You can read some RFID tags from a longer range. Most RFID tags have two divisions. The first component is an embedded circuit used for storing information and can be used for extra tasks. The second part is an antenna used to receive and transmit the signalRFID tags offer a wide range of apps ; for instance, they can be used to improve the effectiveness of inventory monitoring and management in the company supply chain management. This includes interrogators (called readers) and tags (called labels) [19],[20]. 


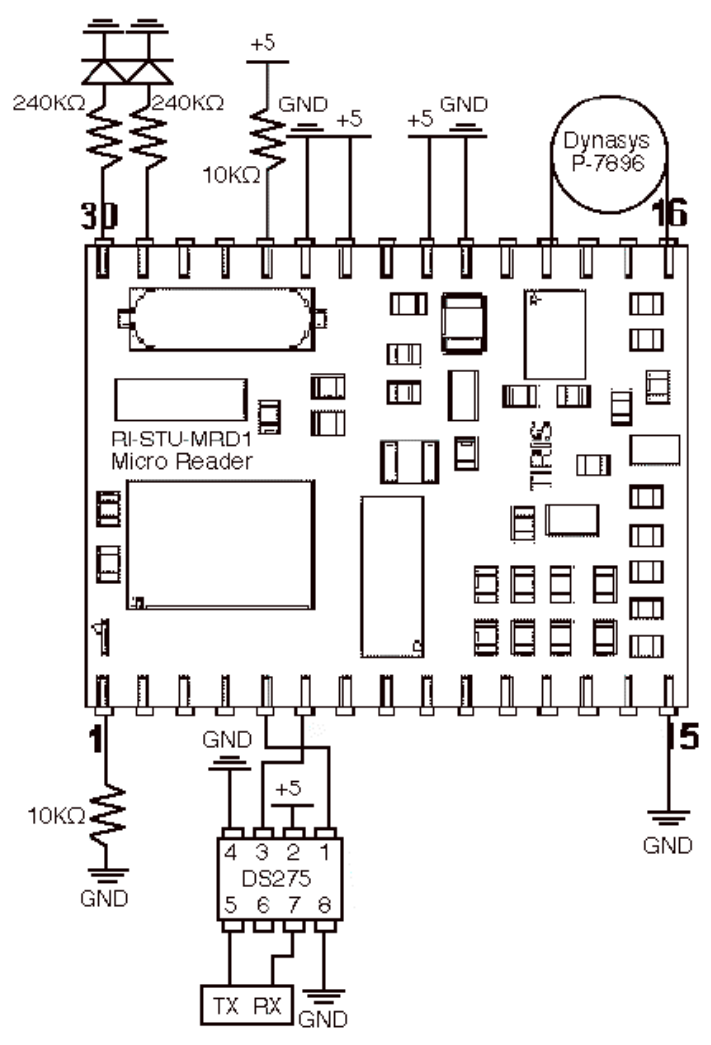

\section{UART}

UART stands foruniversal asynchronous receiver/transmitter. It functions as an "asynchronous receiver/transmitter". It is used for the translation of Data between the parallel and the serial form. UARTs are consistent with other communication norms such as EIA RS-232.A UART is frequently a separate integrated circuit can be component of an integrated circuit. The serial port of any peripheral device to the computer can be used for serial communication. UARTs are currently given in the microcontrollers themselves. The Universal Asynchronous Receiver / Transmitter (UART) controller acts as the main part of the serial communication subsystem on a computer. The UART uses information bytes as input and transmits bits one by one in a serialmanner. At the receiving end, another UART is placed to re-assemble all the bits to the original bytes form. Digital data (bits) can be serially transferred using a single wire or other medium at a reduced price compared to parallel transmission using multiple cables. UART can be used to convert the transmitted data from its serial to parallel form at each end of the link. Each UART is supplied with a shift register, which is the main method for converting serial and parallel forms.

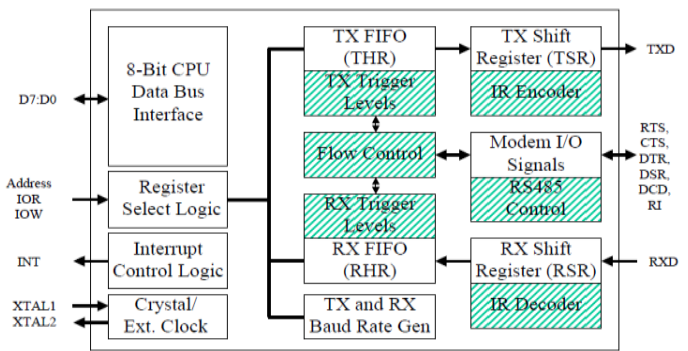

Fig3.4 Block Diagram of Max232

\section{E. MAX232}

The MAX232 is used to convert signals from the serial port of the RS-232 cable into a form that makes the signal adaptive for use in TTL-based digital logic circuits. The MAX232 acts as a dual conductor or receiver circuit and is used to convert RX, TX, CTS and RTS signals.

Driver circuits are used to provide the required voltage level for RS 232 inputs (approx. $\pm 7.5 \mathrm{~V}$ ) from a single $+5 \mathrm{~V}$ supply via charge pumps and internal capacitors supplied. On the chip. This helps to make it useful for the RS-232 to be installed in devices so that voltages beyond $0 \mathrm{~V}$ to $+5 \mathrm{~V}$ are not needed. As a result, simple power supply design is sufficient to drive the RS-232. The RS-232 input voltage level (as high as $\pm 25 \mathrm{~V}$ ) is decreased by the receiver to the normal $5 \mathrm{~V}$ TTL level. The typical threshold value of these receivers is $1.3 \mathrm{~V}$, with a typical hysteresis value of $0.5 \mathrm{~V}$.

\section{F. LCD}

Liquid crystal display (LCD) comprises of a thin, flat panel. Electronic information such as information, images, and moving images can be viewed using these LCDs. Its primary applications include computer monitors and televisions. It can also be used in instrument panels and as displays for airplane cockpits, etc. It is also used in our day-to-day consumer devices such as phones, video games, clocks, gaming systems, watches and calculators.

\section{FUTURE ENHANCEMENTS}

In this paper, we successfully designed a computer classroom of the energy-saving system by RFID. This concept of RFID based power consumption can also be extended for software companies.The computers present in the software agency are accessed at the same time. There are cases where some user may forget to shutdown the computer which may result in wastage of more energy and money. This technology can be used to design an automatic energy-saving system for the companies also.

\section{CONCLUSION}

This solution can save a lot of energy, correspondingly, we also saving the much expense of electricity if this system can extensively popularize each computer classroom and lab.We can Implement Energy Efficiency and Carbon Reduction; It can reduce the considerable Electricity charges and carbon dioxide emissions and slow warming of the Earth. This automatic energy-saving system has been designed using The RFID radio frequency identification technology to be used in any computer laboratory. When computers are not in use, the computer will shut down or automatically shut down. That's why we can save unnecessary energy waste and decrease carbon dioxide emissions and slow global warming. Reader connected to the server through microcontroller helps the user to access their respective system.

\section{REFERENCES}

1. G Kongkham, D. \& Sundararajan, M. 2019, "Distributed wideband sensing method for faded dynamic spectrum access", International Journal of Innovative Technology and Exploring Engineering, vol. 8, no. 10, pp. 4309-4312.

2. Balaji, S., John Paul Praveen, A. \& Mohanraj, R. 2019, "Recognizable 
proof and analysis of palm print in biometric authentication system using bayes techniques", International Journal of Innovative Technology and Exploring Engineering, vol. 8, no. 9 Special Issue 3, pp. 1126-1129.

3. Kavitha, G., Priya, N., Velvizhi, R. \& Allin Geo, A.V. 2019, "Paralle computation in correspondence and signal processing", International Journal of Innovative Technology and Exploring Engineering, vol. 8, no. 9 Special Issue 3, pp. 1136-1139.

4. Hema, R., Sundararajan, M. \& Balaji, S. 2019, "Smartphone control robot with automatic firing gun", International Journal of Innovative Technology and Exploring Engineering, vol. 8, no. 9 Special Issue 3, pp. 625-627.

5. Kaliyamurthie, K.P., Sundar Raj, B., Velvizhi, R. \& Shanmugapriya, K. 2019, "Dual band paper substrate CPW antenna for wireless applications", International Journal of Innovative Technology and Exploring Engineering, vol. 8, no. 9 Special Issue 3, pp. 605-608.

6. Geo, A.V.A., Arunachalam, A.R., Michael, G. \& Elankavi, R. 2019, "Evaluating architecture using compact modalities", International Journal of Innovative Technology and Exploring Engineering, vol. 8, no. 9 Special Issue 3, pp. 836-838.

7. Theivasigamani, S., Jeyapriya, D. \& Anita Davamani, K. 2019, "Anamoly analyzing and exploring for wireless sensor networks", International Journal of Innovative Technology and Exploring Engineering, vol. 8, no. 9 Special Issue 3, pp. 1116-1118.

8. Jeyapriya, D., Theivasigamani, S., Velvizhi, R. \& Nandhini, P. 2019, "Program detection in wireless feeler networks", International Journal of Innovative Technology and Exploring Engineering, vol. 8, no. 9 Special Issue 3, pp. 1194-1195.

9. Gowri Sankaran, B., Karthik, B. \& Vijayaragavan, S.P. 2019, "Image compression utilizing wavelet transform", International Journal of Innovative Technology and Exploring Engineering, vol. 8, no. 10, pp. 4305-4308

10. Gowri Sankaran, B., Karthik, B. \& Vijayaragavan, S.P. 2019, "Weight ward change region plummeting change for square based image huffman coding", International Journal of Innovative Technology and Exploring Engineering, vol. 8, no. 10, pp. 4313-4316.

11. Hema, R., Sundararajan, M. \& Balaji, S. 2019, "Smartphone control robot with automatic firing gun", International Journal of Innovative Technology and Exploring Engineering, vol. 8, no. 9 Special Issue 3, pp. 625-627.

12. Rangaswamy, K. \& Rajabhushanam, C. 2019, "Congestion control in wireless network using TCP friendly rate control (TFRC)", International Journal of Recent Technology and Engineering, vol. 8, no. 2 Special issue 3, pp. 1598-1602.

13. Tamil Selvan, S. \& Sundararajan, M. 2019, "Performance Parameters of 3 Value 8t Cntfet Based Sram Cell Design Using H-Spice", International Journal of Recent Technology and Engineering, vol. 8, no. 2 Special issue 5, pp. 22-27.

14. Vinoth, V.V. \& Kanniga, E. 2019, "Steganographical techniques in hiding text images - system", International Journal of Recent Technology and Engineering, vol. 8, no. 2, pp. 6535-6537.

15. Saravana, S., Balaji, S., Arulselvi, S. \& John Paul Praveen, A. 2019, "Reliable power quality monitoring and protection system", International Journal of Innovative Technology and Exploring Engineering, vol. 8, no. 9 Special Issue 3, pp. 644-645

16. Sundaramoorthy, A. \& John Wiselin, M.C. 2019, "Single patch antenna with multiple feed", International Journal of Innovative Technology and Exploring Engineering, vol. 8, no. 9, pp. 1743-1747.

17. Velavan, R., Bharanidharan, S. \& Sheeba, B. 2019, "EMF pollution Causes, effects and protection", International Journal of Innovative Technology and Exploring Engineering, vol. 8, no. 9 Special Issue 3, pp. 1166-1168.

18. Veer, R.A., Arulselvi, S. \& Karthik, B. 2019, "Construction of ensemble square classification approaches in MIMO OFDM", International Journal of Engineering and Advanced Technology, vol. 8, no. 5, pp. 2039-2041.

19. Agitha, W. \& Kaliyamurthie, K.P. 2019, "Improved energy efficient in WBAN using MAC with cloud computing", International Journal of Innovative Technology and Exploring Engineering, vol. 8, no. 8, pp. 2405-2408.

20. Kastro, G.G. \& Wiselin, M.C.J. 2019, "Design and analysis of stub loaded resonator", International Journal of Recent Technology and Engineering, vol. 8, no. 1 Special Issue4, pp. 272-283.

\section{AUTHORS PROFILE}

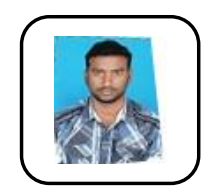

R.S. Sidharthraj, Assistant Professor, Department of Electronics and Communication Engineering, Bharath Institute of Higher Education and Research, Chennai, India.

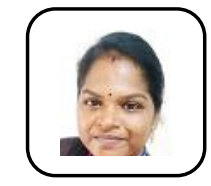

K. Subbulakshmi, Assistant Professor, Department of Electronics and Communication Engineering, Bharath Institute of Higher Education and Research, Chennai, India.

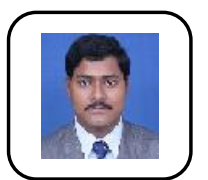

R. Mohan Raj, Assistant Professor, Department of Electronics and Communication Engineering, Bharath Institute of Higher Education and Research, Chennai, India. 